\title{
SUCCESS FACTORS OF E-COMMERCE - DRIVERS OF THE CONVERSION RATE AND BASKET VALUE
}

\author{
Darius Zumstein and Wolfgang Kotowski \\ Zurich University of Applied Sciences, Institute of Marketing Management \\ Theaterstrasse 17, 8400 Winterthur, Switzerland
}

\begin{abstract}
Digital Commerce is growing dynamically in most countries and industries, both new and established online retailers are constantly expanding their product ranges and revenues. Different digital and customer services are essential to increase the success of online shops, as a representative survey among 300 online shops indicates. More than the half of the e-shops offer free shipping and product reviews, and already one third provides personalized content or product offers. To increase sales, the majority of online shops provide discount codes and recommendation of complementary and alternative products. Surprisingly, every third online shop implemented an online configurator for mass customized products or services. Three quarters answered that digital analytics is important for analyzing and controlling digital business. Analyzing different success factors, this contribution shows that customer-, service- and data-driven online shops generate higher conversions rates and revenues. Product reviews, discount codes, personalization and the recommendation of alternative products lead to significant higher conversion rates. Most online retailers are selling on different distribution channels like e-mail, phone, digital marketplaces and pick-up stores. Finally, successful omnichannel vendors are using a variety of digital marketing channels such as search engine optimization and advertising, newsletter marketing, social media and influencer marketing.
\end{abstract}

\section{KEYWORDS}

E-commerce, Digital Commerce, Success Factors, Digital Marketing, Digital Services, Online Shop, Conversion Rate

\section{INTRODUCTION}

The digital transformation changed many classic business models and new ones found their origin. Thereby, digitization enabled new possibilities of transactions and processes (Duffy \& Dale, 2002), which in turn evoked new forms of value creation (Amit \& Zott, 2001, p. 493). With the increasing success of new digital business models, the attention grew in marketing and organizational research regarding the success factors that caused this success. In the new millennium, an increasing number of scientific publications addressed topics such as the success factors (and risks) for e-commerce strategies (Kim \& Lee, 2002; Viehland, 2000). Success factors in e-commerce were identified in SMEs (Bianchi \& Bivona, 2002; Cosgun \& Dogerlioglu, 2012; Stockdale \& Standing, 2006), in business-to-business (Eid, Trueman, \& Moneim Ahmed, 2002; Janom \& Zakaria, 2009), in business-to-consumer (AlGhamdi, Nguyen, \& Jones, 2013), and finally in mobile commerce (Feng, Hoegler, \& Stucky, 2006; Søilen, Kovacevic, \& Jallouli, 2012). A further differentiation of research on success factors in e-commerce occurred according to industries, such as banking (Shah, Braganza, \& Morabito, 2007) or retail. However, all this kind of success factors were mostly implicitly understood and described as static. This study wants to raise the question whether the success factors are static or whether they are dynamic and are subject to change, which in turn should be investigated.

The success of the e-commerce companies manifests itself in ongoing steady growth. While brick-and-mortar retailing generally stagnates or declines, electronic commerce continues to boom. Numerous new online shops and virtual marketplaces are entering the global market, which is developing rapidly, fundamentally and dynamically. Worldwide e-commerce revenues are doubling every four years and reached more than 3'418 billion Dollars in 2018 (eMarketers 2019). In 2019, German e-commerce revenues grew up to 58 billion Euros (HDE \& GfK 2019) and Swiss e-commerce revenues up to 10 billion Swiss Francs (VSV 2019). Research focused on this growth in e-commerce too (Ho, Kauffman, \& Liang, 2007), among SMEs, in 
omnichannel commerce (Leimstoll \& Wölfle 2017) or in mobile commerce (Einav, Levin, Popov, \& Sundaresan, 2014).

Despite of this extensive research on success and failure in e-commerce, it remained unconsidered that the success factors may themselves be subject to change. The growth of e-commerce itself, but also the emergence of new technologies and business models may provoke this change (Chen, Guo, \& Tang, 2019). New studies are looking at new methodological approaches to investigating current success factors (Sharma \& Aggarwal, 2019), to describe them with the help of service-dominant logic (Festa, Cuomo, \& Metallo, 2019) or other frameworks (Varela, Araújo, Vieira, Manupati, \& Manoj, 2017). Therefore, the contribution of this study is to examine if and how success factors in e-commerce are subject to change like the mentioned business models. The understanding of the change of success factors in e-commerce should be a contribution to the theoretical and practical understanding about them in general.

The remainder of the article presents the theoretical and practical understanding of success factors in digital businesses and change, on the basis of which the subsequent empirical analysis was conducted. This empirical analysis examines success factors in e-commerce using the example of 300 online retailers in Switzerland in two surveys in 2018 and 2019. This comparison, although short in time, already shows changes in the success factors due to the strong changes and growth in e-commerce. Therefore the conclusion does not only deal with the identified success factors but also with their changes. The research outlook indicates opportunities, based on this study, to investigate the changes in success factors in e-commerce in more detail in the future.

\section{SUCCESS FACTORS AND GROWTH}

Although success factors were already investigated in the 1960s (Daniel, 1961), it was not until Anthony et al. (1972) and Rockart (1979) and that research was deepened again in relation to management control systems. Meibodi and Monavvarian (2010) define success factors as critical for the economic success of a company. They assume that success factors influence permanent measures in companies to achieve their goals. In contrast to this assumption of success factors that tend to be static, Rockart and Cerscenzi (1983) define two types of success factors that already call this picture into question: (1) success factors that dynamically adapt to daily problems, and (2) success factors that relate to future developments and therefore have a considerable degree of uncertainty. Furthermore, Leidecker and Bruno (1984) note that success factors may not be clearly identifiable. They also explain that success factors can be found and related to each other at three levels: the company, the industry and the economic socio-political environment. These three levels are subject to constant change, just as companies, industries and entire environments are constantly changing. It is therefore surprising that these changes have not yet been related to success factors as such.

Exogenous and endogenous growth theories likewise refer to those three levels. Exogenous or neoclassical growth theory understands growth, on the one hand, as the result of changes in the external environment of the company (Solow, 1956; Swan, 1956). Endogenous growth theory, on the other hand, assumes that growth (also) arises internally from an economic system (Romer, 1994). It assumes an intensive exchange between technological change and economic life (Aghion \& Howitt, 1999), which stimulates growth. We understand digitalization as such a technological change and the emerging e-commerce as the result of an exchange between this technological change and the economic system of economic markets. Therefore, the dynamics underlying this endogenous growth must also be taken into account when examining success factors.

\section{RESULTS OF THE ONLINE RETAILER STUDY}

\subsection{Method and Sample}

The rapid change and growth in e-commerce in recent years was an important reason to carry out this empirical study for the first time in 2018 (Zumstein \& Steigerwald 2018) and to repeat it in 2019. The aim of the research was to find out more about the sales channels (discussed in section 3.2), marketing instruments (in section 3.3) and of services of Swiss online shops (in section 4). The question "What does digital commerce look like from the practical online retailers perspective?" was investigated by the Zurich University of Applied Sciences in cooperation with Lucerne University of Applied Sciences, the University of Applied Sciences Northwestern 
Switzerland and the sponsor Swiss Post. From a management point of view, the research project addressed all online shops with a .com or .ch domain, which are registered and are selling in Switzerland. The focus was not only on large online shops, but also on smaller and medium-sized online shops and companies (SMEs). The data was collected from February to June 2019 in a quantitative online survey using the tool UniPark.

In 2019, in total 3'326 online shops have been contacted. The net participation was 674, 307 CEOs and e-commerce managers filled out the survey, 279 all of the 29 questions. Therefore, the sample (n) size was 279.

\subsection{Sales Channels}

More than $85 \%$ of the Swiss online retailers operate the online shop by their own, $12 \%$ have outsourced it (see figure 1). A surprising number of $77 \%$ accept orders via $e$-mail. Especially in the business-to-business (B2B) sector, e-mail orders are widespread. At eight out of ten e-shops it can also be order by phone. Surprisingly, $58 \%$ of online retailers sell personally, for example through sales representatives or sales staff. In addition, three out of five e-shops sell through high street stores and shopping malls. Omnichannel management remains a big topic for the majority of the companies. In 2019, the merchants were asked, whether they also sell through Google Shopping or Facebook Marketplace, whereupon 52\% agreed.

Every third retailer still receives orders via fax machines. In B2B companies, this share is even higher. Moreover, a third continues to send print catalogs with ordered talons, although this medium is relatively cost expensive. Almost $30 \%$ of retailers offer a native app with an order function in the app stores. Trade fairs are still common in B2B, and every fourth sells on physical markets. Orders via messenger services like WhatsApp are becoming increasingly popular. Voice assistants such as Google Assistant, Siri, Alexa (Amazon Echo), Cortana, Bixby (Samsung) or HiVoice (Huawei), are still very seldom provided and used to purchase products.

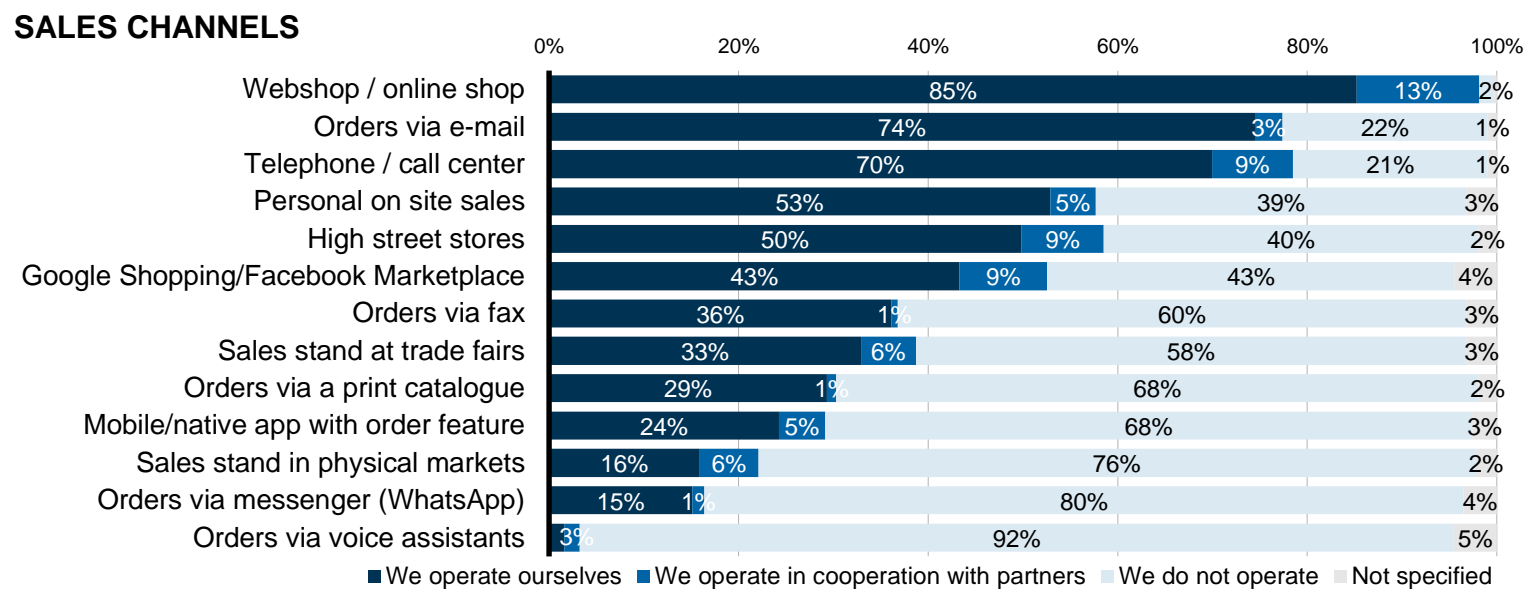

Figure 1. Sales Channels of Online Shops $(n=341)$

\subsection{Marketing Instruments of E-Commerce}

The relevance of different marketing instruments used to promote the e-shop and to generate online sales was a crucial question to the online retailers. It turns out that search engine optimization, shortly SEO, is the most important online marketing tool for almost all online shops (compare figure 2). SEO is understood here as all measures and actions that aim to make the website of an online shop appear on the top of the organic search results of search engines such as Google. Google is an important source of traffic and revenues for all, both small and large e-shops across all industries. It is a critical success factor for the most online shops to be top ranked on Google for various, specific, product- and sales-relevant search terms (keywords).

In addition, search engine advertising (SEA) is the third most important marketing instrument. SEA is very relevant for two-thirds of asked retailers. Most of the online shops are booking Google ads to promote their brand, products or services. The results of search engine advertising, also known as sponsored links, keyword ads or text ads usually generates relevant sales for e-shops. Since Google has a market share of more than $90 \%$ in most European countries (StatCounter 2018), online retailers are forced to run Google ads campaigns. 
Another classic online marketing instrument that is relevant for almost all online shops is newsletter or e-mail marketing: two-thirds of the respondents consider it to be very relevant, another quarter as quite relevant.

Social media advertising, i.e. ads on social platforms such as Facebook, Instagram, Twitter, LinkedIn or $\mathrm{XING}$, is another standard instrument of digital marketing, which almost all online shops use. The opportunity to target attractive customer segments on social media with a high reach is both used by small and large e-shops. Using social media advertising and classical banner advertising, visitors on third-party websites are (re-)targeted to the online shop. For the majority, remarketing technology is an important marketing instruments to increase sales. Two offline marketing channels are listed in the top 10 marketing instruments of online shops only: those of direct marketing (relevant for 57\%) and those of advertisements or newspaper advertising (relevant for 39\%). Some online shops still provide information and product offers printed on flyers or product catalogs.

Within a short time, influencer marketing has been established as a relevant marketing instrument for two-thirds of the online shops. In B2C, Instagram is the most widely used platform on which influencers show products or services for money. Many, mostly large shops consider sponsoring as an effective marketing tool, at least when it comes to increase reach, brand awareness and brand image. In affiliate marketing, ads are displayed and billed by affiliate systems, based on the number or revenues of sales.

In recent years, traditional forms of advertising such as outdoor advertising (poster/billboard advertising) as well as television and radio advertising have become less important. In figure 2 less than $10 \%$ of the retailers still classify them as relevant. Surprisingly, video advertising (e.g. YouTube ads) is quite irrelevant for e-shops. Similarly, sponsored content (native advertising) is not very popular among online retailers.

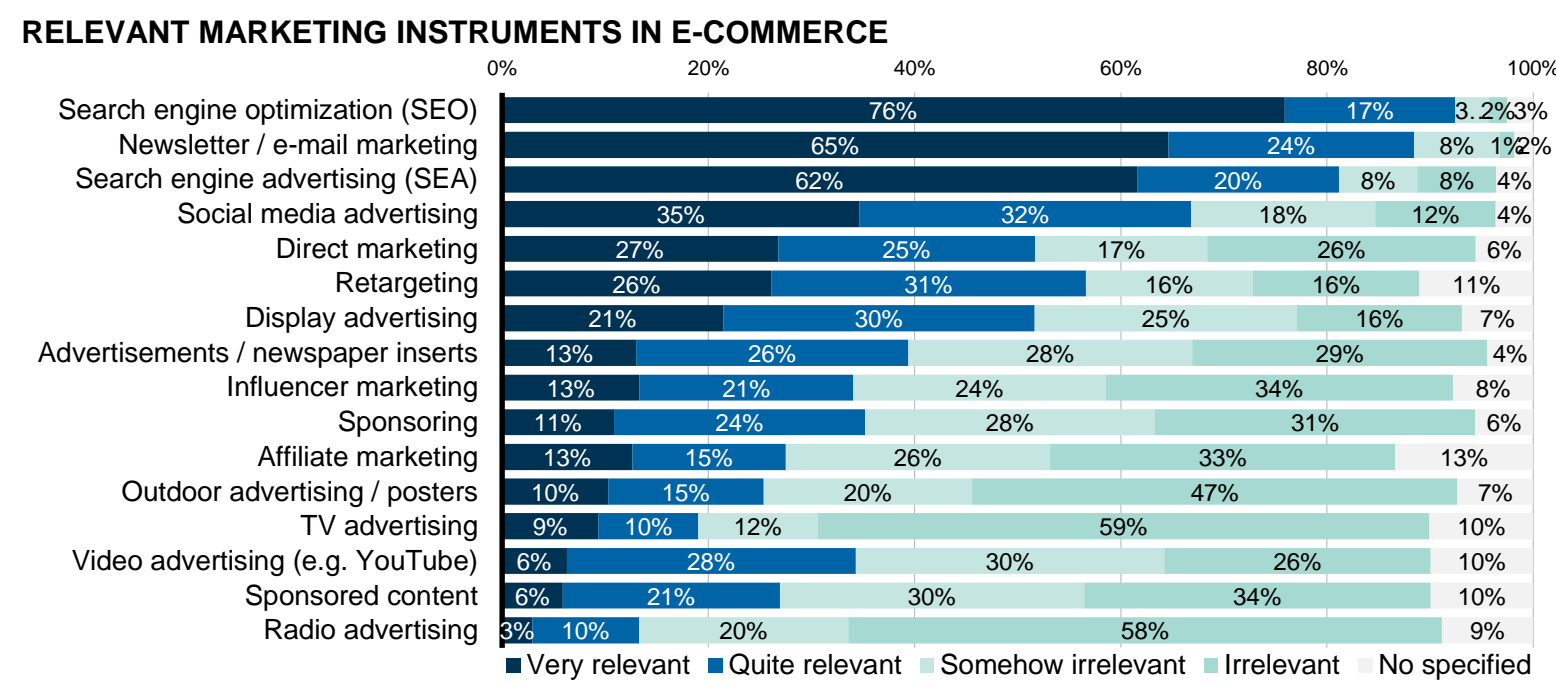

Figure 2. Relevance of Marketing Instruments in E-Commerce $(n=282)$

\section{SUCCESS FACTORS IN E-COMMERCE}

\subsection{Services of E-Commerce}

In this study, $78 \%$ of online shops offer customer services (in figure 3a). Followed by discount codes, customer services and support are the most often used service in e-commerce. In e-businesses, where customers do not know their customers personally, trust is important and can be increased by product reviews. According to this study, product reviews and ratings are the fourth most important digital service. Another service offered by the majority of online retailers is free shipping (or at least free delivery with a minimal order quantity in figure $3 b)$. More and more online retailers (28\%) are also offering free returns, a new standard set by Zalando.

With a certain range of products, an e-shop should implement a recommendation function. In this sample, $48 \%$ do so. The recommendation of complementary products significantly increases the basked value and the 
recommendation of alternative products the conversion rate (see chapter 4.2). The likelihood that a customer will find the right product is much higher, if he is also offered similar products during his search.

Another relevant service is personalization: $38 \%$ of the web shops are personalizing their content or offers. The number of online shops who is providing a product configurators, that allow users to digitally tailor their products or services according to their needs, is continuously increasing too: already $34 \%$ mentioned that they are offering a product or service configurator. Every fourth e-shop sometimes gives a giveaway, or a free gift respectively. Similarly, every fourth web shop offers vouchers from third parties on the confirmation page and/ or attach them to delivered parcels. With discount codes on subsequent orders ( $48 \%$ in figure $3 \mathrm{~b}$ ) and loyalty programs $(22 \%$ in figure $3 \mathrm{a})$, retailers are trying to bind customers to the store and to increase sales.

Volume discounts, product bundling and optimized search, for instance auto suggest, fuzzy search or filter functions, are further often used sales-promoting instruments (in figure $3 \mathrm{~b}$ ). However, $72 \%$ of the online shops not yet send any reminder (e.g. an e-mail reminder) to their customers after a shopping cart abandonment. Effective scarcity effects, in which an online offer is limited to a certain quantity or time, are used by $24 \%$ of the asked e-commerce managers. Payments by installment are provided by $17 \%$ of the considered shops only.

\section{A) SERVICES OF ONLINE SHOPS}

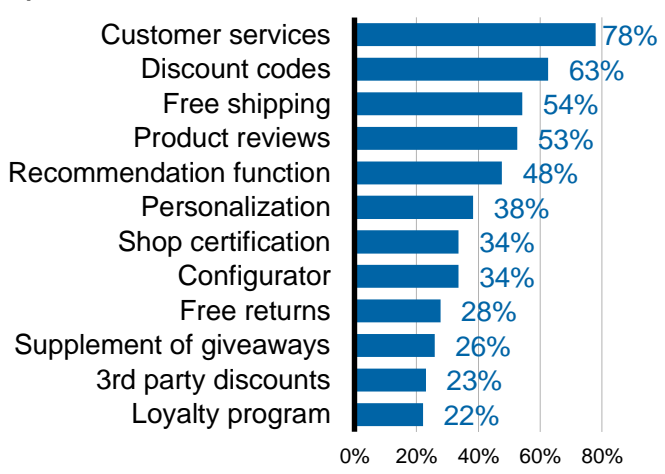

\section{B) SALES-PROMOTING INSTRUMENTS}

Recommendation of complementary products Recommendation of alternative products Free delivery with a minimal order quantity Discount codes (e.g. on subsequent order) Volume discount Product bundling Optimized search function Reminder after basket abandoned Minimum order quantity Scarcity effects Payment by installments

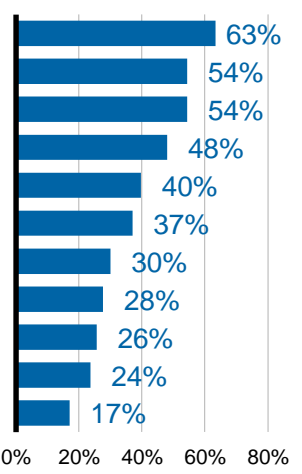

Figure 3. a) Services and b) Sales-promoting Instruments in E-Commerce $(n=282)$

\subsection{Drivers of the Conversion Rate}

The conversion rate (CR) is defined as the share of visitors of an online shop, who purchased a product in a time period. In e-commerce, the conversion rate is one of the most important key performance indicators.

The majority of the online shops $(62 \%)$ have small or medium conversion rates between $1 \%$ and $4,9 \%$ (see figure 4a; typically selling fashion, sportswear, cosmetics, computer and electronic devices). Every tenth shop has low conversion rates under $1 \%$ (often furniture and accessories). Nearly one quarter has quite or very high conversion rates between $5 \%$ and $20 \%$ (e.g. consumables, tools or books). Analysing the data, this research projects identified seven drivers of the conversion rate, which increase the conversion rate significantly.
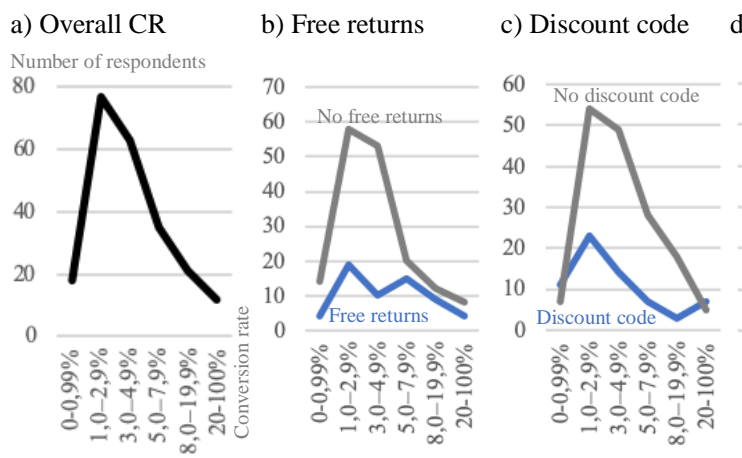

d) Certification e) Personalization f) Product reviews g) Recommend.

Figure 4. Conversion Rate of E-Shops without and with b) Free Returns, c) Discount Codes, d) Certification, e) Personalization, f) Product Reviews, g) Recommendation of Alternative Products and h) Digital Analytics 
Therefore, following nine hypotheses are derived and visualized in the conceptional model of figure 5.

1. H1: Discount codes increase the conversion rate. Discounts and vouchers are an effective marketing and pricing instrument that should be well considered and managed. This research shows that online shops providing discount codes have notable higher conversion rate than online shops without (see figure $4 \mathrm{c}$ ).

2. H2: E-shop certification and seals of quality increase the conversion rate. Data show that certified e-shops have significantly higher conversion rates than shops without certification (compare figure 4d).

3. H3: Free shipping increases the conversion rate. Free shipping has a psychological effect that buyers may get something for free. Therefore they are more likely to buy in a e-shop (shown in figure 4a).

4. H4: Free returns increase the conversion rate. If online shops provide free returns, their conversion rate is significantly higher than online shops without this service (in figure 4b).

5. H5: Personalization increases the conversion rate. E-shops with personalized content or offers tend to have a higher CR, since they increase relevance for customers and decrease complexity (figure 4e).

6. H6: Product reviews increase the CR. Customer products reviews and ratings increase trustworthiness. Online shops with product reviews have significantly higher CR than those without reviews (figure $4 \mathrm{f}$ ).

7. H7: Recommendation of alternative products increases the CR. Since customer are more likely to find the right product, recommendation of similar products increases the CR for e-shops (in figure 4g).

8. H8: Digital analytics increases the CR. Without use of digital analytics systems like Google Analytics, Adobe Analytics or Matomo, e-shops are on a blind flight. By analyzing and using digital analytics data, retailers have significantly higher conversion in contrast to less data-driven online retailers.

9. H9: Higher CR lead to higher online revenues. Shown in figure 5, there is strong positive correlation between the (total) conversion rate and online revenues and profits, if fix/overhead costs are stable.

\subsection{Drivers of the Basket Value and Revenues}

Analyzing possible impact factors of the average basket value (order value), following drivers and further six hypotheses have been identified and considered in a conceptional model on the right side of figure 5.

1. H10: Digital marketing instruments increase online revenues. Digital commerce implicates digital marketing: Eight of the ten most used and important instruments of marketing are digital ones.

2. H11: Recommendation of additional products increases online revenues. Recommending additional products and equipment on a product page, the basket/order value can be significantly improved.

3. H12: Discount codes on subsequent orders increase online revenues. Incentives of loyalty programs and discount codes on subsequent orders can generate further customer purchases and revenues.

4. H13: Shopping days increase online revenues. Remarkably, $42 \%$ of 300 asked e-shops provide special offers on Black Friday, and 22\% at Cyber Monday and Valentine's Day. This has huge revenue impact.

5. H14: Volume discounts increase online revenues. Providing volume discounts, this can incentive web shop user to add a higher amount of products to the basket and increase the order value.

6. H15: Increase of the average basket value leads to higher online revenues. Consequently, there is a positive correlation between BV and online revenues (and profits, if fix/overhead costs remain stable).

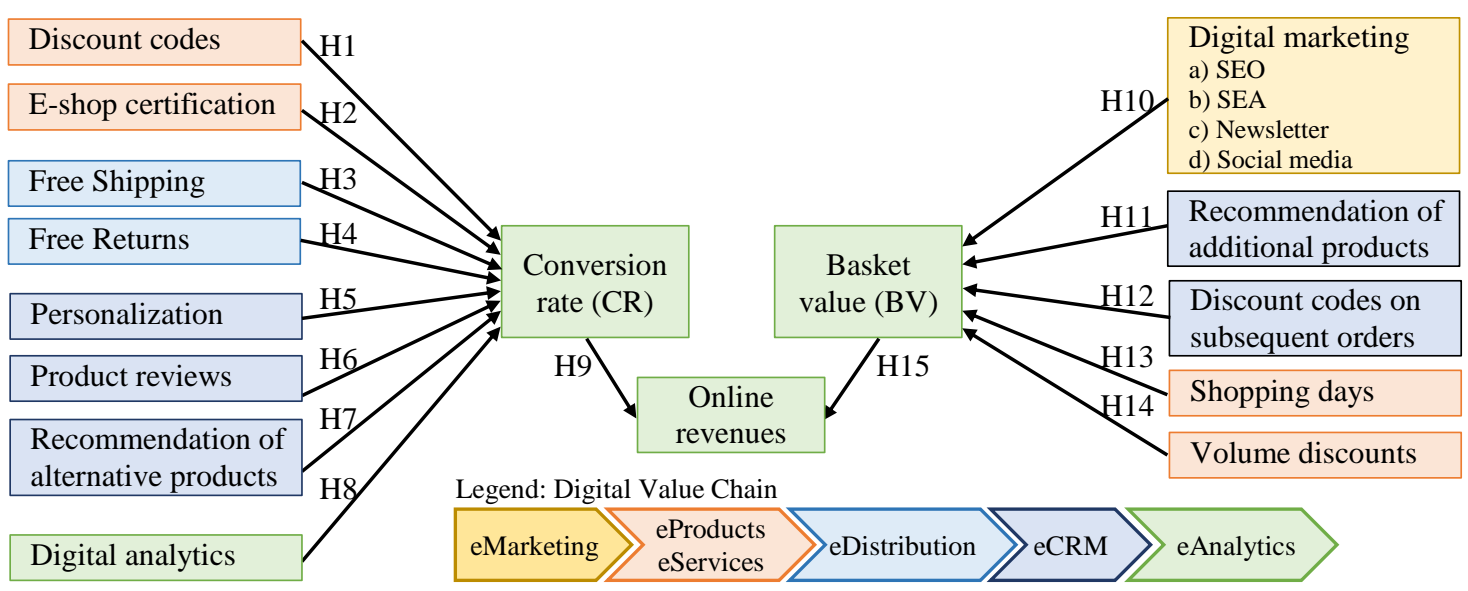

Figure 5. Conceptional Model of Success Factors in E-Commerce 


\section{CONCLUSION}

\subsection{Recommendations for Online Shops and Retailers}

Analyzing the results of this ongoing research, following ten recommendations for online shops can be derived.

1. Offer free shipping and free returns: An online shop should test, if free returns increases its conversion rate. Since the return rate is very low for most of the product groups and categories (38\% of the shop have a return rate lower than $1 \%$ ), the risks and additional expenses are usually limited.

2. Provide discount codes: Online shops should provide discount codes as an important and effective marketing and pricing instrument. It is a way to attract new customers (e.g. discount codes for newsletter inscription) and to retain existing customers (e.g. discount code for loyal, engaged or valuable customers). Discount codes may lead to lower revenue, but to significantly higher conversion rates.

3. Offer «Black Friday» deals: The majority of e-shops offers special deals during shopping days. If a shop does not want to lose (potential) customers to competitors, attractive deals/offers should be promoted.

4. Enable product reviews: Enable and promote product reviews and customer engagement. They increase trust and thus promote sale of products. Only 5\% of the surveyed shops with product reviews have a low conversion rate below $1 \%$. For shops without ratings, the share is more than twice as high with $12 \%$.

5. Certify the online shops: E-shops should communicate certification, awards, customer satisfaction labels or other seals of approval on their website. This reduces possible doubts, and creates trust and value.

6. Personalize content and offers: Based on user and usage data, information, content and/or product offers of e-shops, newsletters and customer portals should be personalized. In e-commerce, personalization is relatively easy to implement and increases the personal relevance and benefits for customers.

7. Orchestrate different sales and marketing channels: All 300 analyzed retailers sell through multiple channels. It is important that these marketing and sales channels are not managed as/in isolated silos.

8. Sell on digital marketplaces: Online shops should check digital marketplaces as additional distribution and sales channel. For the majority of manufacturers and dealers, the question is no longer whether they sell through marketplaces like Amazon or AliExpress, but which assortments on which marketplaces.

9. Implement recommendation systems: In e-commerce, recommendation systems are an effective tool. The data-based recommendation of complementary or similar products is used by many customers.

10. Analyse digital analytics data: If a retailer wants to analyze and effectively control the success of its web shop, he needs to professionally manage digital analytics and customer data. Data are the fundament for effective sales and marketing as well as for many applications and future sales opportunities.

\subsection{Further Research and Outlook}

The identified success factors and hypotheses of this research project should be systemized, analyzed in details and tested statistically in a structural model. In figure 5, a draft version of a conceptional model is presented.

Moreover, not only value drivers but also risks and challenges in e-commerce should be investigated. Online shops are faced with increasing channel and platform complexity and inefficiency, which is difficult to manage. Marketing complexity (e.g. the number of platforms, instruments and campaigns) is increasing, as well as the prices in digital advertising (see Heierli et al., 2019). Especially SMEs often cannot afford high Google and Facebook advertising costs and they have difficulties to gain reach, awareness, clicks and transactions.

Another emerging field of research is ecology in e-commerce. The huge number of parcels sent and returned is damaging the environment. Moreover, the waste of package and $\mathrm{CO}^{2}$ emissions of logistics are increasing too. However, there is little research which systematically addresses these negative sides of e-commerce.

\section{REFERENCES}

Aghion, P., Howitt, P. (1999). Endogenous Growth Theory. Cambridge, Mass.: The MIT Press.

AlGhamdi, R., Nguyen, A., Jones, V. (2013). A Study of Influential Factors in the Adoption and Diffusion of B2C

E-Commerce. International Journal of Advanced Computer Science and Applications, 4(1), pp. 89-94.

Amit, R., Zott, C. (2001). Value creation in e-business. Strategic Management Journal, 22(6-7), pp. 493-520. 
Anthony, R. N., Dearden, J., Vancil, R. F. (1972). Management Control Systems. Homewood: Irwin.

Bianchi, C., Bivona, E. (2002). Opportunities and pitfalls related to e-commerce strategies in small-medium firms: a system dynamics approach. System Dynamics Review, 18(3), pp. 403-429.

Chen, J., Guo, Z., Tang, Y. (2019). Research on B2C E-Commerce Business Model Based on System Dynamics. American Journal of Industrial and Business Management, 9, pp. 854-874.

Colla, E., Lapoule, P. (2012). E-commerce: exploring the critical success factor. International Journal of Retail \& Distribution Management, 40(11), pp. 842-864.

Cosgun, V., Dogerlioglu, O. (2012). Critical Success Factors A!ecting e-commerce Activities of Small and Medium Enterprises. Information Technology Journal, 11(12), pp. 1664-1676.

Daniel, D. R. (1961). Management Information Crisis. Harvard Business Review, 39(5), pp. 111-121.

Duffy, G., Dale, B. G. (2002). E-commerce processes: a study of criticality. Ind. Management \& DS, 102(8), pp. $432-441$.

Eid, R., Trueman, M., Moneim Ahmed, A. (2002). A cross-industry review of B2B critical success factors. Internet Research: Electronic Networking Applications and Policy, 12(2), pp. 110-123.

Einav, L., Levin, J., Popov, I., Sundaresan, N. (2014). Growth, Adoption, and Use of Mobile E-Commerce. 126th Annual Meeting of the American Economic Assiciation, pp. 489-494.

Feng, H., Hoegler, T., Stucky, W. (2006). Exploring the Critical Success Factors for Mobile Commerce. In: Proceedings of the International Conference on Mobile Business (ICMB'06), p. 8.

Festa, G., Cuomo, M. T., Metallo, G. (2019). The service-dominant logic perspective for enhancing the e-commerce of wine - A test/application on the Italian wine sector. Journal of Business Research, 101, pp. 477-484.

Heierli, R., et al., 2019. Complecity and dynamics in marketing, Swiss marketing leadership study 2019 (in German), Institute for Marketing Management, Zurich University of Applied Sciences, 2019.

Ho, S.-C., Kauffman, R. J., Liang, T.-P. (2007). A growth theory perspective on B2C e-commerce growth in Europe: An exploratory study. Electronic Commerce Research and Applications, 6, pp. 237-259.

Janom, N., Zakaria, M. S. (2009). B2B E-commerce Readiness Assessment Indicators based on the Critical Success Factors. Proceeding of Int. Conference on Electrical Engineering and Informatics (ICEEI 2009), 8. Bangi Selangor.

Kim, J., Lee, J. (2002). Critical design factors for successful e-commerce systems. Behavior \& IT, 21(3), pp. $185-199$.

Kreutzer, R., 2018. Practice orientierted online marketing (in German), 3rd edition, Springer Gabler, Wiesbaden.

Leidecker, J., Bruno, A. (1984). Identifying and Using Critical Success Factors. Long Range Planning, 17(1), pp. $23-32$.

Meibodi, L. A., Monavvarian, A. (2010). Recognizing critical success factors (CSF) to achieve the strategic goals of SAIPA Press. Business Strategie Series, 11(2), pp. 124-133.

Leimstoll, U., Wölfle, R., 2017. Changing Atttidues of Retailers Towards Cross-Channel Commerce and its Success, In: Proceedings of $15^{\text {th }}$ International Conference e-Society 2017, pp. 39-48, Budapest.

Rockart, J. F. (1979). Chief Executives Define Their Own Information Needs. Harvard Business Rev., 57(2), pp. 81-93.

Rockart, J. F., \& Crescenzi, A. D. (1983). A Process for the Rapid Development of Systems in Support of Managerial Decision Making. Cambridge, Mass.: MIT Sloan School of Management.

Romer, P. M. (1994). The Origins of Endogenous Growth. Journal of Economic Perspectives, 8(1), pp. 3-22.

Shah, M. H., Braganza, A., Morabito, V. (2007). A survey of critical success factors in e-Banking: an organisational perspective. European Journal of Information Systems, 16(4), pp. 511-524.

Sharma, H., \& Aggarwal, A. G. (2019). Finding determinants of e-commerce success: a PLS-SEM approach. Journal of Advances in Management Research.

Søilen, K. S., Kovacevic, M. A., \& Jallouli, R. (2012). Key success factors for Ericsson mobile platforms using the value grid model. Journal of Business Research, 65(9), pp. 1335-1345.

Solow, R. M. (1956). A Contribution to the Theory of Economic Growth. Quarterly J. of Economics, 70(1), pp. 65-94.

Stockdale, R., Standing, C. (2006). A classification model to support SME e-commerce adoption initiatives. Journal of Small Business and Enterprise Development, 13(3), pp. 381-394.

StatCounter, 2018. Marketshare of the Top 5 Search Engines in Switzerland in 2018, Statista.

Swan, T. W. (1956). Economic Growth and Capital Accumulation. Economic Record, 32(2), pp. 334-361.

Varela, M. L. R., Araújo, A. F., Vieira, G. G., Manupati, V. K., Manoj, K. (2017). Integrated Framework based on Critical Success Factors for E-Commerce. Journal of Information Systems Engineering \& Management, 2(1), pp. 1-9.

Viehland, D. W. (2000). Critical Success Factors for Developing an e-Business Strategy. Research Letters in the Information and Mathematical Sciences, 1, pp. 1-7.

Zumstein, D., Steigerwald, A.: Swiss Online Retailer Survey 2018: A Study of the Lucerne University of Applied Sciences, Institute of Communication \& Marketing. Results available under: https://e-commerce.post.ch/onlinehandel-2019/en/. 